\title{
Simulation Model for Evaluating the Response of Management Options on the Demersal Resources of Tamil Nadu Coast
}

\section{T.V. SATHIANANDAN* and J. JAYASANKAR}

Fishery Resource Assessment Division, Central Marine Fisheries Research Institute, Kochi - 682 018, Kerala, India.

\begin{abstract}
The response of different management options on demersal fish catch in Tamil Nadu was examined using simulation model and time series data on catch and effort of demersal resources in Tamil Nadu during 1989-2005. For the simulation study surplus, production model and spectral models were used to simulate effort, yield and biomass. Genetic algorithm was used to estimate parameters of surplus production model. Effort, biomass and yield were simulated for the period 2006 to 2015 under different levels of effort such as reducing by $25 \%, 50 \%$, and $75 \%$ of present level increasing by $25 \%, 50 \%, 75 \%$ and $100 \%$ of present level and also for the present level. The simulation results revealed that when the level of exploitation is kept at $25 \%, 50 \%, 75 \%$, and $100 \%$ of the present level, the yield falls below the maximum sustainable yield (MSY) level and the biomass is kept above its MSY level. When the exploitation level is increased by $25 \%$ of the present level of exploitation, the yield falls below the MSY level in the years up to 2013 and the biomass remains above that at MSY level. But at this level of exploitation, the yield falls above the MSY level and the biomass falls below its MSY level for the years 2014 and 2015. The optimum exploitation level was worked out as $91.25 \%$ of the present level of exploitation.
\end{abstract}

\section{Introduction}

Systems analysis and simulation techniques have been applied in marine fisheries management as a tool to assist resource managers for evaluating proposed management actions. Using information available about the fishery and related aspects, simulation models attempt to estimate resulting future changes due to implementation of different management options. Prior knowledge about the effect of implementation of these management options on the fishery resources is very much essential to implement the correct management measure. A quantitative assessment of the effect of different management options on the fishery resources is possible through simulation modeling of the system. Here, a simulation study was conducted to examine the effects of restrictions imposed on fishing effort on the demersal fishery resources of Tamil Nadu, India.

\footnotetext{
*Corresponding Author.

Email : sattvsedpl@hotmail.com
} 
With regard to marine fish production, the state of Tamil Nadu stands fourth among the maritime states, after Kerala, Gujarat, and Maharashtra. During the period 2001-2005, the estimate of average annual landings in the state is 3,55,451 t (tonnes), which accounts for $14.45 \%$ of the total production in the country. The average demersal landing during 2001-2005 is 1,08,561 t, which is about $30.91 \%$ of the marine fish landings in the state. Important demersal resources, based on landings in the state, are silverbellies (30.88\%), perches $(29.49 \%)$, elasmobranchs $(14.14 \%)$, croakers $(7.64 \%)$, goatfishes (5.54\%), lizardfishes (4.06\%), catfishes (2.68\%), and pomfrets (2.48\%). Important gears that caught demersal resources are mechanized trawlnet, mechanized hooks and lines, multiday trawlnet, outboard hooks and lines, and outboard gillnets. On an average during 2001-2005, about $61.07 \%$ of the demersal landings were by mechanized trawlnets, $14.74 \%$ by outboard gillnets, $6.8 \%$ by outboard hooks and lines, and $5.93 \%$ by multiday trawlnets.

Application of simulation model into fisheries research was considered by many authors. Grant et al. (1981) gave a generalized bio-economic simulation model for annualcrop fisheries and demonstrated its use in marine fisheries management. George \& Grant (1983) described a stochastic simulation model for the dynamics of brown shrimp (Penaeus aztecus) in Galveston Bay, Texas. Parker (1986) used data from the Celtic sea and formulated a dynamic simulation model to describe the accumulation of chlorophyll within the thermocline. Carothers \& Grant (1987) explored the relationship between recruitment seasonality and ordination of alternative management policies through a general stochastic simulation model.

Ackley (1995) developed a simulation model of the Bering Sea fishery as a quantitative means for estimating the impacts of management actions on catch and bycatch. Christensen (1998) constructed two mass-balance trophic models to describe the Gulf of Thailand ecosystem and validated the dynamic simulation model, Ecosim, to predict ecosystem level changes following changes in fishing pressure. Senina et al. (1999) developed a stochastic simulation model for the community of competing anchovy Engraulis encrasicolus and sprat Clupeonella delicatula in the Azov Sea in Russia and investigated their extinction risk on the basis of time series of population abundance and environmental factors that influence reproduction.

Beare et al. (2000) examined the potential of real-time performance indicators in the Australian northern prawn fishery using a stochastic optimal control model of the fishery. Chen et al. (2000) developed a fuzzy logic model with genetic algorithm for analyzing stock-recruitment relationships of southeast Alaska pink salmon (Oncorhynchus gorbuscha) and West Coast Island Pacific herring (Clupea pallasii) stocks. Azadivar et al. (2002) used simulation-based optimization to determine an area management policy with optimal fishing rate for the sea scallop resources of Georges Bank in Northwest Atlantic Ocean. Mishra et al. (2002) developed a bio-energetic 
dynamic simulation model for the growth of penaeid shrimps based on an existing model on tilapia growth, and it was consisting of submodels for molting, feed consumption, digestion and biosynthesis, energy metabolism, oxidation, and growth. Prager (2002) made a comparison of results from logistic and generalized surplus production models by the simulation of stock of swordfish Xiphias gladius in the North Atlantic Ocean. Schnute \& Haigh (2003) used a simulation model based on compound binomial-gamma distribution to assist the planning and design of ground fish trawl survey.

\section{Materials and Methods}

The basic surplus production model (Schaefer 1954) is used for calculation of biomass, fishing mortality, and yield in the simulation. The model is given by

$$
\frac{d B_{t}}{d t}=r B_{t}\left(1-\frac{B_{t}}{K}\right)-F_{t} B_{t}
$$

where $B_{t}$ is the biomass at time $t$ (year), $r$ is the intrinsic rate of increase of the stock, $K$ is the carrying capacity, and $F_{t}$ is the fishing mortality rate. The recursive expressions for calculating biomass and yield given by Prager (1994), based on the model parameters initial biomass $B_{0}$, carrying capacity $K$, intrinsic growth rate $r$, and catchability coefficient $q$ using time series data on catch and effort, were followed in this study. The maximum sustainable yield (MSY), biomass at MSY, fishing mortality that generates MSY, and the fishing effort corresponding to MSY were estimated (Prager 1994) as given below.

$$
M S Y=\frac{K r}{4} ; \quad B_{M S Y}=\frac{K}{2} ; F_{M S Y}=\underset{2}{r} ; \quad f_{M S Y}=\frac{r}{2 q}
$$

A genetic algorithm developed was used for estimation of the parameters of the surplus production model using time series data on catch and effort of demersal resources of Tamil Nadu during 1989-2005 obtained from the database of the Central Marine Fisheries Research Institute, Cochin. Effort series for demersal catch were computed using the effort of mechanized trawlnet, mechanized hooks and lines, multiday trawlnet, outboard hooks and lines, and outboard gillnets, which mainly catch demersal resources. Management options can be introduced only on the effort series on hours of operation of the gears. For simulating effort series for future years, spectral time series models were adopted by estimating model parameters and residual variance using time series data on effort of these gears. The spectral model used has the expression

$$
y_{t}=a_{0}+\sum_{i=1}^{k}\left[a_{i} \operatorname{Sin}\left(2 \pi \lambda_{i} t\right)+b_{i} \operatorname{Cos}\left(2 \pi \lambda_{i} t\right)\right]+\varepsilon_{t} .
$$

The error term $\varepsilon_{t}$ was assumed to be from a normal distribution with zero mean and constant variance for simulation purpose. For implementation of the genetic algorithm, spectral model estimation and simulation of effort, biomass, fishing mortality, and yield computer software were developed in-house in $\mathrm{C}++$. For the prediction of 
future biomass and yield, the effort scenario was simulated first, which was then used for the yield forecast. The simulation of effort was carried out as follows. From the spectral model that was exclusively fitted on the effort time series, the mean effort for a future year was computed with the parameters. Then, the distributional aspect of effort sequence was assumed to be normal with standard error estimated from the effort series. With each of the predicted mean effort, 1000 numbers of simulated normal values with appropriate error were added to get the sequence of 1000 effort values for each year of forecast. For each value of the simulated effort, biomass, fishing mortality, and yield were calculated using the estimated surplus production model, and averages of these quantities were recorded. Such simulations were carried out for each of the future years from 2006 to 2015. Restrictions on hours of operations were introduced by multiplying the simulated effort by a suitable factor before calculation of biomass, fishing mortality, and yield.

\section{Results and Discussion}

Estimates of parameters of surplus production model obtained through the genetic algorithm using time series data on catch and effort for demersal resources of Tamil Nadu and the estimates of spectral model parameters used for modeling effort series are given in Table 1.

Table 1. Estimates of parameters of surplus production model and spectral model

\begin{tabular}{llllrrr}
\hline \multicolumn{2}{l}{ Parameter Estimate } & No & Frequency & Periodogram & Sine term & Cos term \\
\hline $\mathrm{B}_{0}$ & 197369.24 & 1 & 0.0588 & 141493 & -16603.51 & -1191.87 \\
$\mathrm{~K}$ & 474003.06 & 2 & 0.1176 & 53593 & 4792.94 & 4096.61 \\
$\mathrm{r}$ & 1.268522 & 3 & 0.2353 & 43819 & 138.69 & -5153.34 \\
$\mathrm{q}$ & 0.000004028 & 4 & 0.4706 & 33695 & 2143.46 & -3334.68 \\
& & 5 & 0.3529 & 29502 & 3375.61 & 807.13 \\
& & 6 & 0.1765 & 29134 & -3427.17 & -48.35 \\
\hline
\end{tabular}

The estimate of MSY for demersal resources in Tamil Nadu calculated using the estimates of surplus production model parameters is $1,50,320 \mathrm{t}$ (tonnes), estimate of biomass corresponding to the MSY level is 2,37,001 t, estimate of fishing mortality rate at MSY level is 0.6343 , and estimate of effort corresponding to MSY level is 1,57,463 hours of operation. Plot of the biomass and yield calculated using the estimated surplus production model along with the observed catch is given in Figure 1. 


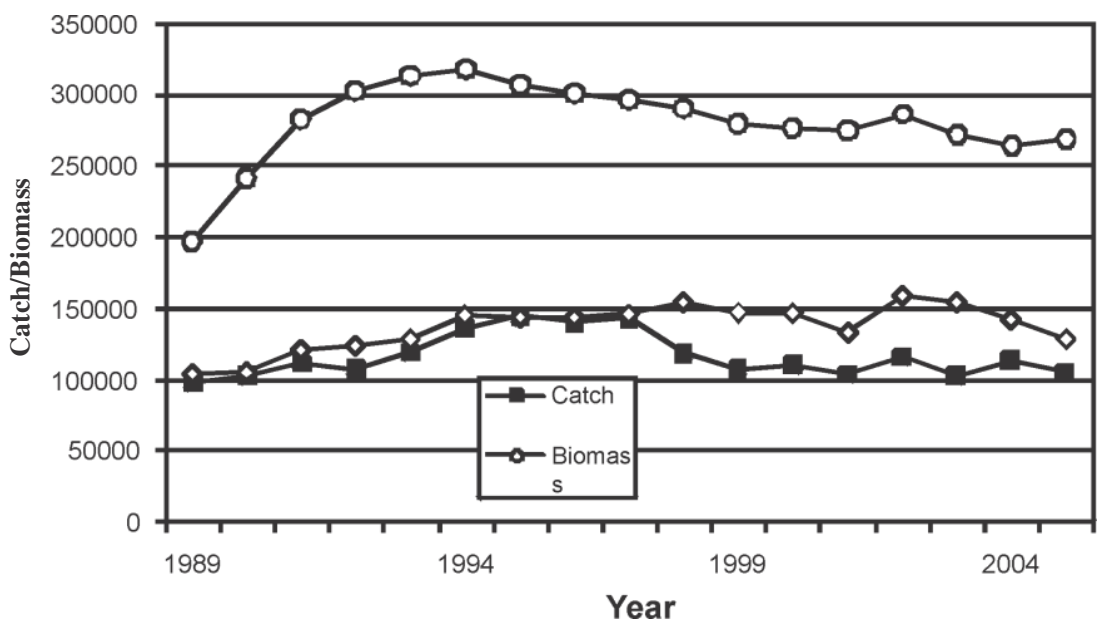

Figure 1. Plot of observed catch along with yield and biomass computed using the estimated surplus production model for the demersal resources of Tamil Nadu

The observed effort series and the corresponding fitted series based on spectral model are shown in Figure 2.

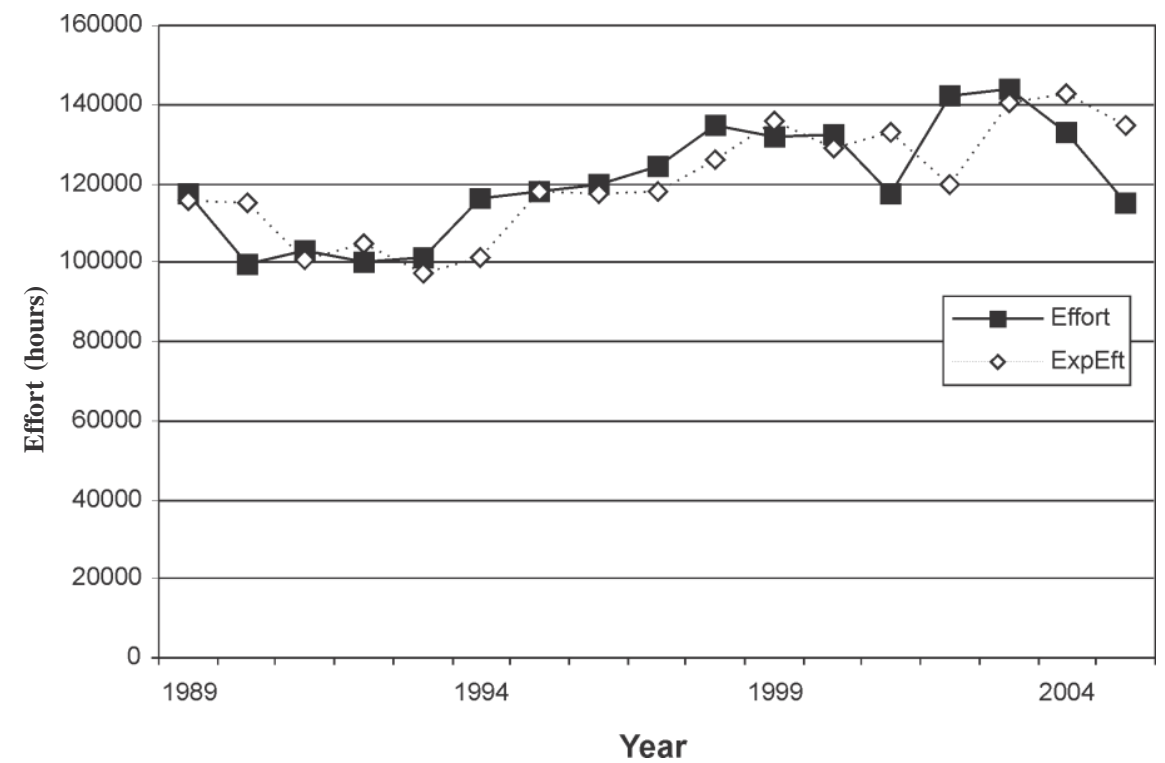

Figure 2. Plot of observed effort and effort computed using the fitted spectral model

Estimates of fishing mortality rate, biomass and expected yield based on the fitted model are given in Table 2. During the period 1996-2005, the observed demersal catch is below the MSY level for all the years. The average annual demersal catch during this period is $1,16,433 \mathrm{t}$, which is far below the MSY. 
Table 2. Estimates of fishing mortality, biomass and yield calculated based on the fitted surplus production model

\begin{tabular}{llll}
\hline Year & $\mathrm{F}(\mathrm{t})$ & Biomass & Yield \\
\hline 1989 & 0.473234 & 197369 & 104625 \\
1990 & 0.399908 & 241940 & 105903 \\
1991 & 0.414505 & 283894 & 122132 \\
1992 & 0.402365 & 303107 & 124592 \\
1993 & 0.407327 & 314682 & 129121 \\
1994 & 0.467437 & 318752 & 146056 \\
1995 & 0.474535 & 307751 & 144375 \\
1996 & 0.482095 & 301587 & 144229 \\
1997 & 0.500229 & 297330 & 147151 \\
1998 & 0.54349 & 291747 & 155137 \\
1999 & 0.531442 & 280622 & 148316 \\
2000 & 0.533488 & 277885 & 147742 \\
2001 & 0.473576 & 276195 & 133727 \\
2002 & 0.57314 & 287251 & 159957 \\
2003 & 0.580032 & 272828 & 155651 \\
2004 & 0.534568 & 264854 & 143015 \\
2005 & 0.464775 & 269660 & 129503 \\
\hline
\end{tabular}

Simulation of the demersal fishery for Tamil Nadu was carried out by generating effort series using the estimated spectral model with a normal error term having zero mean and constant variance for different levels of effort such as $25 \%, 50 \%, 75 \%, 100 \%$, $125 \%, 150 \%, 175 \%$, and $200 \%$ of the current level of exploitation. One thousand such simulations were made, and for each simulation mortality, biomass and yield series were generated for the period from 2006 to 2015, and the averages of the results of simulation are given in the Table 3 for different levels of exploitation.

Table 3. Fishing mortality, biomass, and yield simulated for different levels of exploitation for the demersal resources of Tamil Nadu

\begin{tabular}{rrrrrrr}
\hline \multicolumn{3}{c}{$25 \%$} & & \multicolumn{3}{c}{$50 \%$} \\
\hline Year & Mortality & Biomass & Yield & Mortality & Biomass & Yield \\
\hline 2006 & 0.1159 & 285781 & 38593 & 0.2317 & 285781 & 73688 \\
2007 & 0.1016 & 371239 & 40196 & 0.2031 & 344048 & 73760
\end{tabular}




\begin{tabular}{|c|c|c|c|c|c|c|}
\hline 2008 & 0.1051 & 413569 & 44362 & 0.2102 & 377674 & 80781 \\
\hline 2009 & 0.0981 & 427884 & 42339 & 0.1964 & 389098 & 77275 \\
\hline 2010 & 0.1018 & 434374 & 44273 & 0.2035 & 396596 & 80816 \\
\hline 2011 & 0.1187 & 435474 & 51396 & 0.2375 & 397485 & 93285 \\
\hline 2012 & 0.1180 & 431483 & 50833 & 0.2362 & 389532 & 91658 \\
\hline 2013 & 0.1186 & 430410 & 51014 & 0.2370 & 387087 & 91570 \\
\hline 2014 & 0.1269 & 429913 & 54367 & 0.2537 & 386040 & 97283 \\
\hline \multirow[t]{2}{*}{2015} & 0.1370 & 427652 & 58320 & 0.2740 & 381652 & 103555 \\
\hline & \multicolumn{3}{|c|}{$75 \%$} & \multicolumn{3}{|c|}{$100 \%$} \\
\hline Year & Mortality & Biomass & Yield & Mortality & Biomass & Yield \\
\hline 2006 & 0.3469 & 285781 & 105430 & 0.4633 & 285781 & 134510 \\
\hline 2007 & 0.3045 & 318418 & 101202 & 0.4063 & 293948 & 122982 \\
\hline 2008 & 0.3153 & 343045 & 109590 & 0.4212 & 309636 & 131340 \\
\hline 2009 & 0.2949 & 351005 & 104837 & 0.3934 & 313588 & 125046 \\
\hline 2010 & 0.3046 & 358863 & 109436 & 0.4068 & 321286 & 130782 \\
\hline 2011 & 0.3553 & 359684 & 125458 & 0.4750 & 321686 & 148879 \\
\hline 2012 & 0.3543 & 348409 & 122584 & 0.4719 & 307401 & 143597 \\
\hline 2013 & 0.3549 & 344311 & 121834 & 0.4745 & 301972 & 142475 \\
\hline 2014 & 0.3807 & 342547 & 128981 & 0.5079 & 299064 & 149543 \\
\hline \multirow[t]{2}{*}{2015} & 0.4105 & 336112 & 135812 & 0.5480 & 290967 & 155829 \\
\hline & \multicolumn{3}{|c|}{$125 \%$} & \multicolumn{3}{|c|}{$150 \%$} \\
\hline Year & Mortality & Biomass & Yield & Mortality & Biomass & Yield \\
\hline 2006 & 0.5787 & 285781 & 160554 & 0.6950 & 285781 & 184192 \\
\hline 2007 & 0.5077 & 271105 & 139567 & 0.6087 & 249494 & 151339 \\
\hline 2008 & 0.5252 & 277971 & 145925 & 0.6322 & 248077 & 155058 \\
\hline 2009 & 0.4909 & 277862 & 138228 & 0.5891 & 243114 & 144869 \\
\hline 2010 & 0.5089 & 284586 & 144681 & 0.6099 & 248306 & 151036 \\
\hline 2011 & 0.5933 & 284193 & 162999 & 0.7125 & 247244 & 168734 \\
\hline 2012 & 0.5898 & 267600 & 155467 & 0.7077 & 228717 & 158443 \\
\hline 2013 & 0.5919 & 260518 & 152901 & 0.7118 & 220087 & 154535 \\
\hline 2014 & 0.6344 & 256684 & 159380 & 0.7603 & 214778 & 158799 \\
\hline 2015 & 0.6854 & 247033 & 164023 & 0.8223 & 204133 & 160935 \\
\hline
\end{tabular}


Plots of observed catch, estimated average biomass, and average yield for different exploitation levels are shown in Figures 3 and 4.

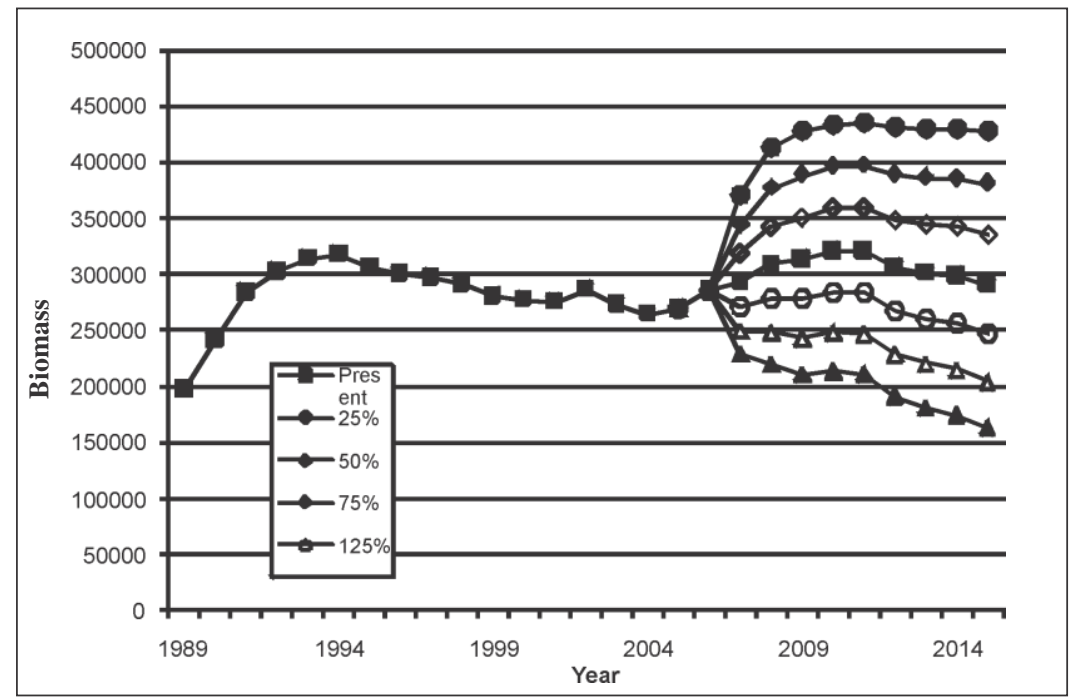

Figure 3. Simulated biomass for demersal fishery in Tamil Nadu for the period up to 2015 for different exploitation levels (as percentages of present level)

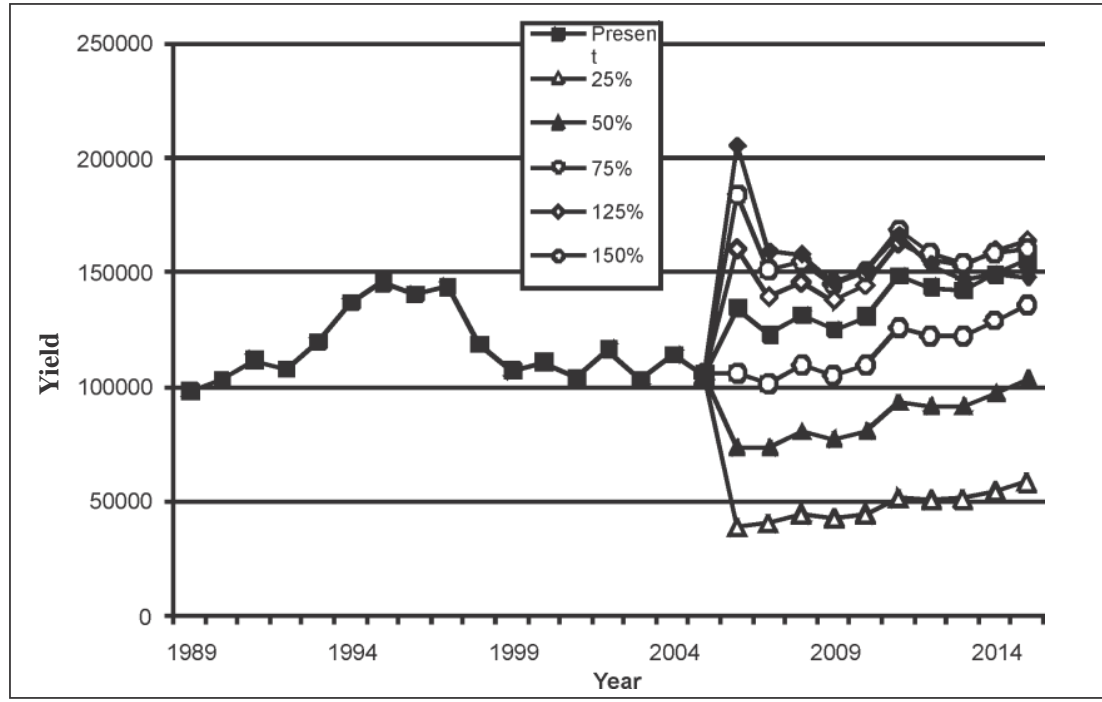

Figure 4. Simulated yield for demersal fishery in Tamil Nadu for the period up to 2015 for different exploitation levels (as percentages of present level)

When the fishery was simulated for the period 2006-2015 maintaining the present level of exploitation, the average annual yield obtained for the period was 1,38,498 $t$ which is below the MSY and the average biomass obtained for the period was 3,04,533 t. The yield obtained in individual years is below the MSY except for the year 2015 in 
which the expected annual yield is 1,55,829 t. The expected minimum yield was 1,22,982 t for the year 2007. In the case when the exploitation level was reduced to $75 \%$ of the present level, the expected yield in all the years from 2006 to 2015 was found to fall below MSY with 1,16,516 t, as the average annual yield for the period and the average annual biomass for the period was 3,38,818 $\mathrm{t}$. The maximum yield expected was $1,35,812 \mathrm{t}$ for the year 2015, and the minimum expected was 1,01,202 $t$ in 2007. Simulation results were also obtained by keeping the exploitation level at $125 \%$ and $150 \%$ of the present level. The simulated average yield during 2006-2015 for 125\% level was 1,52,373 $\mathrm{t}$ and for $150 \%$ level was $1,58,794 \mathrm{t}$ both falling above MSY level. The maximum expected yield for these two exploitation levels was 1,64,023 t in 2015 and 1,84,192 $\mathrm{t}$ in 2006, respectively. In these cases, the expected average annual yields were above MSY in most of the years. The annual average biomass during the period 2006-2015 in the two cases was 2,71,333 and 2,38,973 t, respectively.

From the above results, it was observed that the optimum level of exploitation is between $75 \%$ of the present level and the present level of exploitation (100\%). To work out the optimum level of exploitation that will retain all the years expected yield below the MSY level, further simulations were carried out for finer divisions of levels of exploitations, and it was found that at $91.25 \%$ of the present level of exploitation, the expected yields for all the years form 2006 to 2015 are below MSY.

\section{Acknowledgment}

The authors wish to express their gratitude to Prof. (Dr.) Mohan Joseph Modayil, Director, Central Marine Fisheries Research Institute, Cochin, for providing facilities necessary for the conduct of the simulation study.

\section{References}

Ackley, D. 1995. Bering Sea fishery simulation model. Alaska Fishery Research Bulletin 2(1):83-86.

Azadivar, F., T. Truong, K.D.E. Stokesbury and B.R. Rothschild. 2002. Simulation based optimization in fishery management. Proceedings of the 2002 Winter Simulation Conference (ed. Y.C.H. Chen, J.L. Snowdon and J.M Chames). Charnes: 525-530.

Beare, S., L. Chapman and R. Bell. 2000. Flexible seasonal closures in the Northern Prawn Fishery. IIFET Proceedings: 1-11.

Carothers, P.E. and W.E. Grant. 1987. Fishery management implications of recruitments seasonality: simulation of the Texas fishery for the brown shrimp, Penaeus aztecus. Ecological Modelling 36:239-268.

Chen, D.G., N.B. Hargreaves, D.M. Ware and Y. Liu. 2000. A fuzzy logic model with genetic algorithm for analyzing fish stock-recruitment relationships. Canadian Journal of Fisheries and Aquatic Sciences 57:1878-1887.

Christensen, V. 1998. Fishery induced changes in marine ecosystem: insight from models of the Gulf of Thailand.

Journal of Fish Biology 53(A): 128-142.

George, L. C. and W.E. Grant. 1983. A stochastic simulation model of brown shrimp (Penaeus aztecus Ives)

growth, movement, and survival in Galveston Bay, Texas. Ecological Modelling 19:41 70.

Grant, W.E., K.G. Isakson and W.L. Griffin. 1981. A general bioeconomic simulation model for annual-crop marine fisheries. Ecological Modelling 3(3): 195-219. 
Mishra, A. K., M. Verdegem and A. van Dam. 2002. A dynamic simulation model for growth of penaeid shrimps. In: Avances en Nutrición Acuícola VI. Memorias del VI Simposium Internacional de Nutrición Acuícola (ed. L.E. Cruz-Suárez, D. Ricque-Marie, M. Tapia-Salazar, M.G. Gaxiola-Cortés and N. Simoes). 3 al 6 de Septiembre del 2002. Cancún, Quintana Roo, México. URL: http://www.educacion.uanl.mx/ publicaciones/maricultura/vi/pdf/A27.pdf

Parker, R.A. 1986. Simulating the development of chlorophyll maxima in the Celtic sea. Ecological Modelling 33:1-11.

Prager, M.H. 1994. A suite of extensions to a nonequilibrium surplus-production model. Fishery Bulletin, 92(2): 374389.

Prager, M.H. 2002. Comparison of logistic and generalized surplus-production models applied to swordfish Xiphias gladius in the North Atlantic Ocean. Fisheries Research, 58:41-57.

Schaefer, M.B. 1954. Some aspects of the dynamics of populations important to the management of commercial marine fisheries. Bulletin of the Inter-American Tropical Tuna Commission, 1(2): 27-56.

Schnute, J.T. and R. Haigh. 2003. A simulation model for designing ground fish trawl surveys. Canadian Journal of Fisheries and Aquatic Sciences, 60:640-656.

Senina, I., Y. Tyutyunov and R. Arditi 1999. Extinction risk assessment and optimal harvesting of anchovy and sprat in the Azov Sea. Journal of Applied Ecology, 36:297-306 